\title{
Improved Nuclear Emergency Management System Reflecting Lessons Learned from the Emergency Response at Fukushima Daini Nuclear Power Station after the Great East Japan Earthquake
}

\author{
Shinichi KAWAMURA ${ }^{1, *}$ and Tadashi NARABAYASHI ${ }^{2}$ \\ ${ }^{1}$ Nuclear Asset Management Department, Tokyo Electric Power Company, 1-1-3 Uchisaiwai-cho, Chiyoda-ku, Tokyo 100-8560, \\ Japan \\ ${ }^{2}$ Division of Energy and Environmental Systems, Graduate School of Engineering, Hokkaido University, Kita-13, Nishi-8, Kita-ku, \\ Sapporo 060-8628, Japan
}

\begin{abstract}
Three nuclear reactors at Fukushima Daini Nuclear Power Station lost all their ultimate heat sinks owing to damage from the tsunami caused by the Great East Japan Earthquake on March 11,2011 . Water was injected into the reactors by alternate measures, damaged cooling systems were restored with promptly supplied substitute materials, and all the reactors were brought to a cold shutdown state within four days. Lessons learned from this experience were identified to improve emergency management, especially in the areas of strategic response planning, logistics, and functions supporting response activities continuing over a long period. It was found that continuous planning activities reflecting information from plant parameters and response action results were important, and that relevant functions in emergency response organizations should be integrated. Logistics were handled successfully but many difficulties were experienced. Therefore, their functions should be clearly established and improved by emergency response organizations. Supporting emergency responders in the aspects of their physical and mental conditions was important for sustaining continuous response. As a platform for improvement, the concept of the Incident Command System was applied for the first time to a nuclear emergency management system, with specific improvement ideas such as a phased approach in response planning and common operation pictures.
\end{abstract}

KEYWORDS: accident, accident management, nuclear reactor, Fukushima Daini Nuclear Power Station, The Great East Japan Earthquake, emergency response, incident command, response planning, response operations, logistics

\section{Introduction}

Due to the damage from the tsunami caused by the Great East Japan Earthquake on March 11, 2011, the normal heat-removal systems of Units 1, 2 and 4, as well as all residual heat-removal

* Corresponding author, E-mail: shinichi.kawamura@tepco.co.jp

DOI : 10.15669/fukushimainsights.Vol.4.473

(C) 2021 Atomic Energy Society of Japan. All rights reserved.

Originally published in Transactions of the Atomic Energy Society of Japan (ISSN 1347-2879), Vol. 15, No. 2, p.84-96

(2016) in Japanese. (Japanese version accepted: November 14, 2015) 
(RHR) systems (there are two systems in each reactor) stopped working at the Fukushima Daini Nuclear Power Station (hereinafter referred to as "Fukushima Daini") and the nuclear reactor went into the "Loss of Ultimate Heat Sink" state. In addition, due to the loss of function of the equipment-cooling systems, the pumps of the emergency core-cooling systems (ECCS) were also disabled. While continuing water injection into the reactors from the condensate storage tanks (CST), the RHR systems whose function was lost were restored with temporary equipment, and the cold shutdown of these reactors was completed successfully by March 15 .

The facts concerning the damage and restoration of equipment in this emergency situation were published by the Tokyo Electric Power Company ${ }^{1)}$. However, this investigation report was compiled with a focus on clarifying the equipment situation, on what is called the hardware side. Therefore, human activities as part of an emergency response, on the software side, have not been organized and analyzed sufficiently.

Concerning the software side, based on what the Tokyo Electric Power Company published, the Japan Nuclear Technology Institute ${ }^{2)}$ conducted an analysis using the m-SHEL model, which is a method for analyzing a root cause to draw a lesson with the objective of preventing a mistake in the emergency response. In addition, the investigative committee of the Atomic Energy Society of Japan ${ }^{3)}$ mainly examined the accident that occurred at Tokyo Electric Power Company's Fukushima Daiichi Nuclear Power Station (hereinafter referred to as "Fukushima Daiichi"), and in the analysis, a study was conducted from the standpoint of human factors.

In an actual emergency response, especially in a situation exceeding the anticipated conditions, a response needs to be initiated with limited information, as well as the available human and material resources, in the early stages when the whole picture of the situation has not yet become clear. Therefore, while executing a response, organized activities to raise awareness regarding the situation to revise the countermeasures sequentially are very important. In addition, in order to secure and reinforce both human and material resources, unified collaboration between activities at the site and logistic support is also important. Furthermore, a system to support an ongoing response in the case of a prolonged situation is also necessary. Therefore, in addition to the past research reports and suggestions, it is important to draw lessons regarding the enhancement of organizational capacity from such perspectives.

In this paper, we analyze the case of Fukushima Daini, where the response to a situation actually exceeding the anticipated conditions succeeded, and consider how to improve the emergency management system for the purpose of improving organizational strength to respond flexibly to emergency situations exceeding the anticipated conditions.

\section{Emergency Response Taken and Lessons Learned at Fukushima Daini}

\section{Investigation Method}

The extent of the damage to significant safety equipment and major operations at Fukushima Daini were clarified in the investigation report issued by the Tokyo Electric Power Company ${ }^{1}$. However, this report failed to sufficiently clarify the organizational activities performed during the emergency. Therefore, we added the records of emergency activities gathered by the information team in the emergency response organization of Fukushima Daini, as well as the testimonies for which there was agreement among the sources regarding the objects of analysis. In this way, we attempted to clarify the whole picture of the emergency activities conducted 
at Fukushima Daini as well as to determine the effectiveness and issues regarding individual activities conducted during the emergency response.

\section{Damage to Fukushima Daini Caused by Tsunami}

Fukushima Daini is located approximately $12 \mathrm{~km}$ south of Fukushima Daiichi along the coast extending over Tomioka Town and Naraha Town of Futaba-Gun, Fukushima Prefecture. At the power station, there are four boiling water reactors (BWR5), and their rated thermal output and electric output are 3,293 MWt and 1,100 MWe per reactor, respectively. On March 11, 2011, when the Great East Japan Earthquake occurred, all four reactors were in operation at the rated outputs.

Among the seismic accelerations observed on the lowermost underground floor of each reactor building, the maximum ones were $277 \mathrm{gal}$ in the horizontal direction and 305 gal in the vertical direction. Detecting these accelerations, all reactors scrammed automatically at 14:48 and all control rods were inserted into the reactor cores. It was confirmed from the records that the scram operation and the condition of the plant systems after the scram were as originally designed, and the operations to effect a cold shutdown were conducted according to the specified procedures. Concerning the external power supply, two Tomioka lines and one Iwaido line were serviceable before the earthquake, but all lines except for one Tomioka line became unserviceable as a result of the earthquake.

After that, the tsunami arrived at the power station (the first wave was visually confirmed to have arrived at 15:22) and caused damage to the safety facilities of each reactor.

Table 1 shows the major damage. The residual heat-removal cooling (RHRC) systems and the residual heat-removal sea water (RHRS) systems for transferring the heat of nuclear reactors to the sea, which is the ultimate heat sink, as well as most of the emergency equipment-cooling water (EECW) systems became inoperable because their power panels and electric motors were underwater due to the inundation of the heat-exchanger buildings located near the water intake. In addition, inoperable cooling systems also disabled the operation of the residual

Table 1 Status of cooling systems at Fukushima Daini Nuclear Power Station after the tsunami

\begin{tabular}{|c|c|c|c|c|c|c|c|c|c|}
\hline \multicolumn{2}{|c|}{ System } & \multicolumn{2}{|r|}{ Unit 1} & \multicolumn{2}{|r|}{ Unit 2} & \multicolumn{2}{|r|}{ Unit 3} & \multicolumn{2}{|r|}{ Unit 4} \\
\hline \multirow{3}{*}{$\begin{array}{l}\mathrm{RHR}(\mathrm{A}) \\
\text { including } \\
\text { cooling } \\
\text { systems }\end{array}$} & RHR(A) & $\triangle$ & $\begin{array}{l}\text { Loss of power source } \\
\text { and cooling system }\end{array}$ & $\triangle$ & $\begin{array}{l}\text { Loss of cooling } \\
\text { system }\end{array}$ & $\triangle$ & $\begin{array}{l}\text { Loss of cooling } \\
\text { system }\end{array}$ & $\triangle$ & $\begin{array}{l}\text { Loss of cooling } \\
\text { system }\end{array}$ \\
\hline & $\begin{array}{l}\text { RHRC/RHRS } \\
\quad(\mathrm{A}, \mathrm{C})\end{array}$ & $\times$ & $\begin{array}{l}\text { Submerge of power } \\
\text { source and motor }\end{array}$ & $\triangle$ & $\begin{array}{l}\text { Loss of cooling } \\
\text { system }\end{array}$ & $\times$ & $\begin{array}{l}\text { Submerge of power } \\
\text { source and motor }\end{array}$ & $\times$ & $\begin{array}{l}\text { Submerge of power } \\
\text { source and motor }\end{array}$ \\
\hline & $\operatorname{EECW}(\mathrm{A})$ & $\times$ & $\begin{array}{l}\text { Submerge of power } \\
\text { source and motor }\end{array}$ & $\times$ & $\begin{array}{l}\text { Submerge of power } \\
\text { source and motor }\end{array}$ & $\times$ & $\begin{array}{l}\text { Submerge of power } \\
\text { source and motor }\end{array}$ & $\times$ & $\begin{array}{l}\text { Submerge of power } \\
\text { source and motor }\end{array}$ \\
\hline \multicolumn{2}{|c|}{ LPCS } & $\triangle$ & $\begin{array}{l}\text { Loss of power source } \\
\text { and cooling system }\end{array}$ & $\triangle$ & $\begin{array}{l}\text { Loss of cooling } \\
\text { system }\end{array}$ & $\triangle$ & $\begin{array}{l}\text { Loss of cooling } \\
\text { system }\end{array}$ & $\triangle$ & $\begin{array}{l}\text { Loss of cooling } \\
\text { system }\end{array}$ \\
\hline \multirow{3}{*}{$\begin{array}{l}\mathrm{RHR}(\mathrm{B}) \\
\text { including } \\
\text { cooling } \\
\text { systems }\end{array}$} & RHR(B) & $\triangle$ & $\begin{array}{l}\text { Loss of cooling } \\
\text { system }\end{array}$ & $\triangle$ & $\begin{array}{l}\text { Loss of cooling } \\
\text { system }\end{array}$ & $\bigcirc$ & Stand-by & $\triangle$ & $\begin{array}{l}\text { Loss of cooling } \\
\text { system }\end{array}$ \\
\hline & $\begin{array}{l}\text { RHRC/RHRS } \\
(\mathrm{B}, \mathrm{D})\end{array}$ & $\times$ & $\begin{array}{l}\text { Submerge of power } \\
\text { source and motor }\end{array}$ & $\times$ & $\begin{array}{l}\text { Submerge of power } \\
\text { source }\end{array}$ & 0 & Stand-by & $\times$ & $\begin{array}{l}\text { Submerge of power } \\
\text { source and motor }\end{array}$ \\
\hline & EECW (B) & $\times$ & $\begin{array}{l}\text { Submerge of power } \\
\text { source and motor }\end{array}$ & $\times$ & $\begin{array}{l}\text { Submerge of power } \\
\text { source }\end{array}$ & $\bigcirc$ & Operation & $\times$ & $\begin{array}{l}\text { Submerge of power } \\
\text { source }\end{array}$ \\
\hline \multicolumn{2}{|c|}{$\mathrm{RHR}(\mathrm{C})$} & $\triangle$ & $\begin{array}{l}\text { Loss of cooling } \\
\text { system }\end{array}$ & $\triangle$ & $\begin{array}{l}\text { Loss of cooling } \\
\text { system }\end{array}$ & 0 & Stand-by & $\triangle$ & $\begin{array}{l}\text { Loss of cooling } \\
\text { system }\end{array}$ \\
\hline \multicolumn{2}{|c|}{ RWCU } & $\triangle$ & $\begin{array}{l}\text { Loss of cooling } \\
\text { system }\end{array}$ & $\triangle$ & $\begin{array}{l}\text { Loss of cooling } \\
\text { system }\end{array}$ & $\triangle$ & $\begin{array}{l}\text { Loss of cooling } \\
\text { system }\end{array}$ & $\triangle$ & $\begin{array}{l}\text { Loss of cooling } \\
\text { system }\end{array}$ \\
\hline \multicolumn{2}{|c|}{$\begin{array}{c}\text { MUWC (alternative } \\
\text { water injection) }\end{array}$} & $\bigcirc$ & Stand-by & $\bigcirc$ & Stand-by & $\bigcirc$ & Stand-by & $\bigcirc$ & Stand-by \\
\hline \multicolumn{2}{|r|}{ RCIC } & 0 & Stand-by & 0 & Stand-by & 0 & Stand-by & 0 & Stand-by \\
\hline
\end{tabular}


heat-removal (RHR) systems and the low-pressure core spray (LPCS) systems. Furthermore, the reactor water cleanup (RWCU) systems also lost their heat-removal function. As a result, in Units 1, 2 and 4, all heat-removal facilities and ECCSs for cooling the reactor cores lost their functions. In this situation, the only facilities that could be used for injecting water into the reactor cores were the reactor core isolation cooling (RCIC) systems and the make-up water condensate (MUWC) systems, which were not designed as ECCS.

The events that occurred after the earthquake, as well as corresponding operations, restoration activities and, logistic support activities (logistics), were almost the same among Units 1, 2 and 4, and Table 2 shows these events chronologically, using Unit 1 as an example. In the following, these responses are analyzed in detail and the lessons learned are discussed.

\section{Emergency Responses Made through Operation and the Lessons Learned}

\section{(1) Assistance to the operators at the main control room}

In this emergency situation, assistance was provided to the operators at the main control room as follows. First, the work management teams, which had their offices near the main control room, rushed there to assist the operators. These teams are the organizations in charge of operation management related to maintenance work. All members of these teams are operators

Table 2 Chronology of events and response actions at Fukushima Daini Unit 1

\begin{tabular}{|c|c|c|c|c|}
\hline Date & Time & Event & Plant Operation & Restoration and logistics \\
\hline \multirow[t]{5}{*}{ March 11} & $14: 48$ & $\begin{array}{l}\text { Reactor auto-trip triggered by } \\
\text { earthquake acceleration. Two out } \\
\text { of three external power line lost } \\
\text { by earthquake damage. }\end{array}$ & $\begin{array}{l}\text { Post-scrum actions and continu- } \\
\text { ous Reactor cooling by Main Con- } \\
\text { denser. }\end{array}$ & \\
\hline & $15: 22$ & $\begin{array}{l}\text { First tsunami wave reached the } \\
\text { site. (repeated until } 17: 14 \text { ). }\end{array}$ & & \\
\hline & $15: 36$ & & $\begin{array}{l}\text { MSIV manually closed. } \\
\text { RCIC manually started. }\end{array}$ & \\
\hline & $16: 15$ & & Reactor Depressurization started. & \\
\hline & about $21: 00$ & & & $\begin{array}{l}\text { Field walkdown started for dam- } \\
\text { age identification. }\end{array}$ \\
\hline \multirow[t]{6}{*}{ March 12} & $0: 00$ & & $\begin{array}{l}\text { Low pressure alternate injection } \\
\text { to Reactor by MUWC started. }\end{array}$ & \\
\hline & about $5: 00$ & & & $\begin{array}{l}\text { Field walkdown completed. Pro- } \\
\text { curement of essential material } \\
\text { for restoration started. }\end{array}$ \\
\hline & $5: 22$ & $\begin{array}{l}\mathrm{S} / \mathrm{C} \text { temperature reached } 100^{\circ} \mathrm{C} \text {. } \\
=\text { Loss of pressure suppression } \\
\text { function of PCV. }\end{array}$ & & \\
\hline & $7: 10$ & & Alternate spray in $\mathrm{D} / \mathrm{W}$ by MUWC. & \\
\hline & $7: 37$ & & Alternate spray in $\mathrm{S} / \mathrm{C}$ by MUWC. & \\
\hline & $18: 30$ & & $\begin{array}{l}\text { Preparatory operations for PCV } \\
\text { venting completed. }\end{array}$ & \\
\hline \multirow[t]{4}{*}{ March 13} & about $7: 00$ & & & $\begin{array}{l}\text { Transportation of essential ma- } \\
\text { terial for restoration completed. }\end{array}$ \\
\hline & about $8: 30$ & & & $\begin{array}{l}\text { Cable laying and motor replace- } \\
\text { ment started for recovering RHR } \\
\text { (B). }\end{array}$ \\
\hline & $11: 32$ & & Alternate spray in $\mathrm{D} / \mathrm{W}$ by MUWC. & \\
\hline & $14: 29$ & & Alternate spray in D/W by MUWC. & \\
\hline \multirow[t]{2}{*}{ March 14} & $1: 24$ & & RHR (B) restarted. & $\begin{array}{l}\text { Restoration of RHR (B) complet- } \\
\text { ed. }\end{array}$ \\
\hline & $13: 40$ & Reactor cold shutdown achieved. & & \\
\hline
\end{tabular}

Note : MSIV : Main Steam Isolation Valve, RCIC : Reactor Core Isolation Cooling System, S/C : Suppression Chamber, D/W : Dry well, MUWC : Make-UP Water Condensate System, PCV : Primary Containment Vessel, RHR (B) : Residual Heat Removal System Div. B. 
and the leaders are qualified as operation managers (shift supervisors). With their operational skills, these teams provided effective assistance to the operators in the main control room in terms of checking the configuration of systems to be operated and reconfirming the overall status of the plant.

In the meantime, a site emergency response organization was set up in the important seismic isolated building adjacent to the administration building of the power station. Figure 1 shows the structure of the emergency response organization at that time. In this organization, the task of the plant operation team is to ascertain the operational circumstances and share them with the emergency response organization as well as to provide technical assistance to the operators under the jurisdiction of the headquarters of the site emergency response organization (Site ERC HQ). Almost simultaneously with the setup of the emergency response organization, those experienced in working as operators were dispatched to the respective main control room from this team. This enabled close and secure coordination between the emergency response organization and the main control room via the dispatched plant operation team members while allowing the operators to concentrate on gaining a clear picture of the overall plant situation and the response operations needed.

Meanwhile, at the site emergency response organization, the information on the current condition of major safety facilities and the status of water injection into the reactors were written on whiteboards so this information could be shared. Figure 2 shows some of the information written at approximately 0:00 am on March 12. On one whiteboard, important information, such as the condition of emergency power sources (high-voltage power panels (M/C), emergency generators $(\mathrm{D} / \mathrm{G})$, and direct current power sources $(\mathrm{DC}))$, the condition of the reactor water injection and heat-removal systems (such as RCIC, RHR, and MUWC), and the condition of emergency water sources (condensate storage tank (CST)) in the respective reactors $(1 \mathrm{u}, 2 \mathrm{u}, 3 \mathrm{u}$ and $4 u$ ) were summarized in an easy-to-read way. In addition to the information shown in Figure 2 , the prediction of the increase in pressure in the primary containment vessels (hereinafter called "containment vessels"), including the prediction of the time when the maximum working pressure would be reached, was also written to share this information. Although the condition of the plants and major operations was announced as needed in the site emergency response

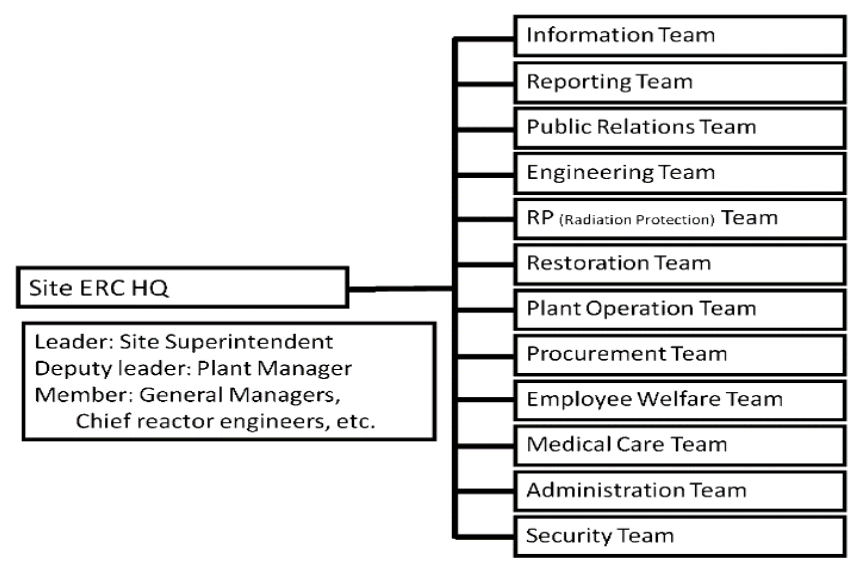

Figure 1 Organizational structure of the Fukushima Daini emergency response organization at the time of the Great East Japan Earthquake in 2011 ERC HQ means Emergency Response Center Headquarters. 


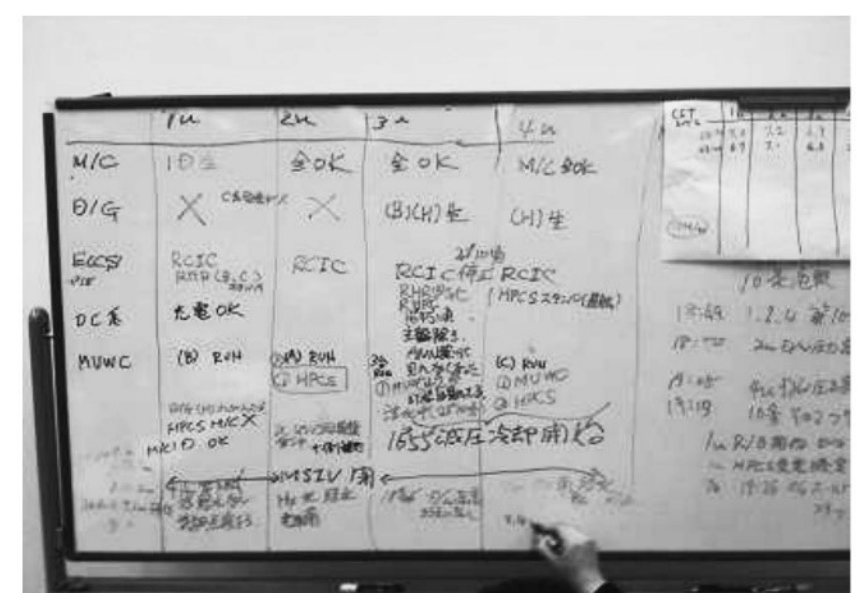

Figure 2 One of the whiteboards summarizing plant system information shared between the Fukushima Daini emergency response organization and operators in the main control rooms

Status of emergency power (M/C: metal-clad switchgear, D/G: diesel generator, DC), ECCS and injection systems such as RCIC and MUWC, injection water source (CST: condensate storage tank), availability of main condenser (status of MSIV: main steam isolation valve), and so on were summarized on this board.

organization, the condition of important facilities was kept visualized at all times. These actions like this is important for all responders and the operators at the main control room to ensure that a common perception of what is occurring is maintained when conducting activities. Besides this, the content discussed by the emergency response organization was conveyed to the main control room by the plant operation team leader. The plant operation team leader, who had been appointed due to his long experience of being responsible for operations, not only conveyed the discussion results at the site emergency response organization but also provided the necessary technical assistance to the main control room.

The main control room is designed so that emergency supervision and operations can be conducted, and the training for such activities is provided to the operators. However, in situations exceeding the anticipated conditions, like this one, constructing a structure to assist the main control room at an early stage by the personnel who have knowledge and experience in plant operation was effective in (1) allowing the operators to concentrate on operations, (2) increasing the reliability of the operators' judgement through reconfirmation, and (3) sharing information closely between the main control room and the site emergency response organization. In addition, establishing a system for sharing information and having a common understanding between the personnel of the site emergency response organization and the operators enabled them to provide appropriate assistance to the main control room. This is considered an important experience and a useful lesson for the future.

\section{(2) Water injection into reactors and containment vessel spray}

In order to secure the safety of the reactors after the scram, it is necessary to place top priority on continuing water injection into the reactors. Figure 3 shows the configuration of the facilities used to maintain continuous water injection into Units 1,2 and 4. The main steam condenser lost its heat-removal function, and the main steam isolation valves (MSIV) were closed to shut off the reactor. In addition, the RHR, RHRC, and RHRS were inoperable as mentioned above, and heat removal using these facilities could not be conducted. On the other hand, the 


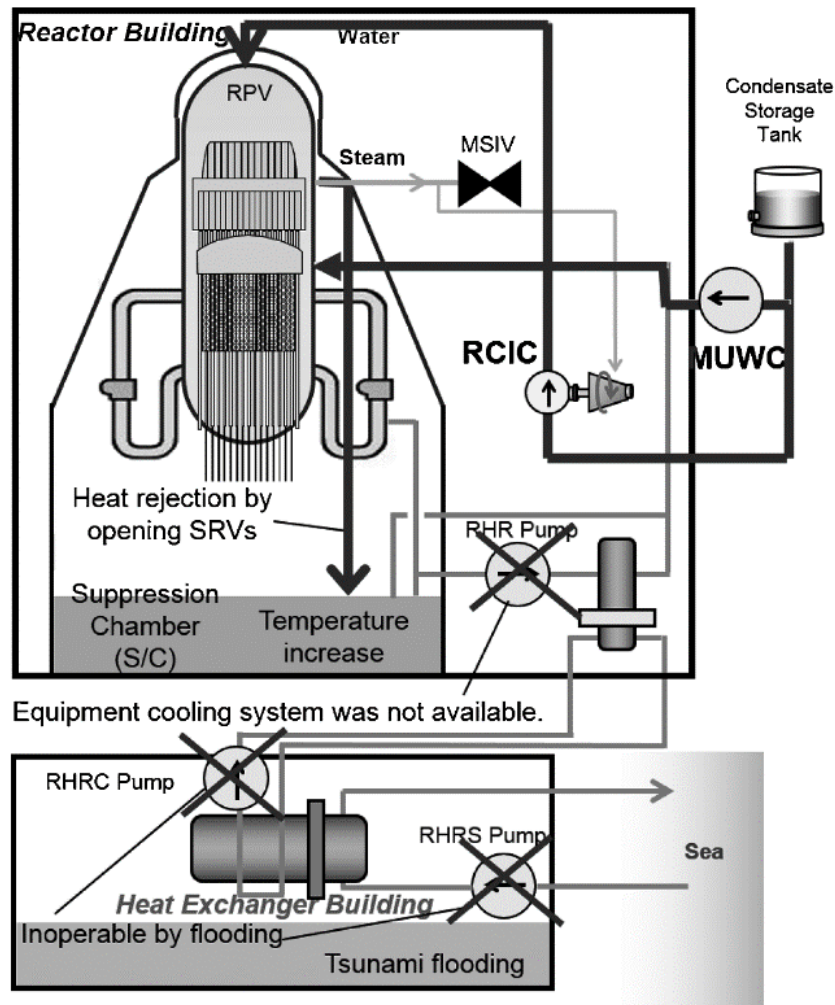

Figure 3 Emergency measures employed at Units 1, 2, and 4 to inject water into the reactor pressure vessels after losing all the safety-related injection and cooling systems including the residual heat-removal systems

steam-turbine-driven RCIC was the only system at each reactor that was operable without any equipment-cooling system among the systems that could inject water into the high-pressure reactor. Therefore, the water in the condensate storage tank was injected into the reactor using this system. After that, the reactor was depressurized using the safety relief valves (SRVs) and the water injection from the condensate storage tank was continued using the low-pressure water-injection system as an alternative to the RCIC.

For this low-pressure water injection, the MUWC that was positioned as an accident management contingency measure was used, although it was not originally designed for injecting water into the reactor. The MUWC pumps are also operable without any equipment-cooling system.

Taking Unit 1 as an example, Figure 4 shows the trend of the reactor pressure and reactor water-injection operation until the cold shutdown of the reactor. The reactor and the containment vessel were cooled with the low-pressure core injection (LPCI) function and the suppression chamber $(\mathrm{S} / \mathrm{C})$ cooling function of system B of the RHR, which was restored on March 14. The same response as that of Unit 1 was also taken for Units 2 and 4. Starting from about 15:36 on March 11, immediately after the heat-removal function of the reactor was lost, water injection through the intermittent operation of the RCIC was conducted. With this situation, the depressurization of the reactor using the SRV was started at 16:15. After that, the injection of water using the MUWC was continued from 0:00 on March 12. This shows that continuous migration from high-pressure water injection to low-pressure water injection was achieved 
with the reactor depressurization in between while maintaining the water injection function.

Figure 5 shows the trend of the reactor water level. Although the reactor water level changed significantly due to the influence of the steam discharge into the suppression chamber associated with the depressurization as well as the intermittent operation of the RCIC system, it was kept higher than the top of active fuel (TAF). In addition, in the nuclide analysis of the reactor water sampled at 8:30 on March 14, it was confirmed that the I-131 and I-132 concentrations, which would change in the case of fuel damage, were not significantly different from the analysis values obtained on February 22, before the emergency situation. This shows that the changeover from high-pressure water injection to low-pressure water injection succeeded as a result of a series of operations and fuel integrity was maintained by continuous cooling.

Meanwhile, as Figure 3 shows, the steam generated in the reactor was led to the suppression chamber in the containment vessel via the SRV. However, because there was no way to cool the water in the suppression chamber, the pressure-suppression function was lost and the pressure in the containment vessel increased after the water reached the saturation temperature.

Taking Unit 1 as an example, Figures $\mathbf{6}$ and $\mathbf{7}$ show the trends of the pressure and temperature

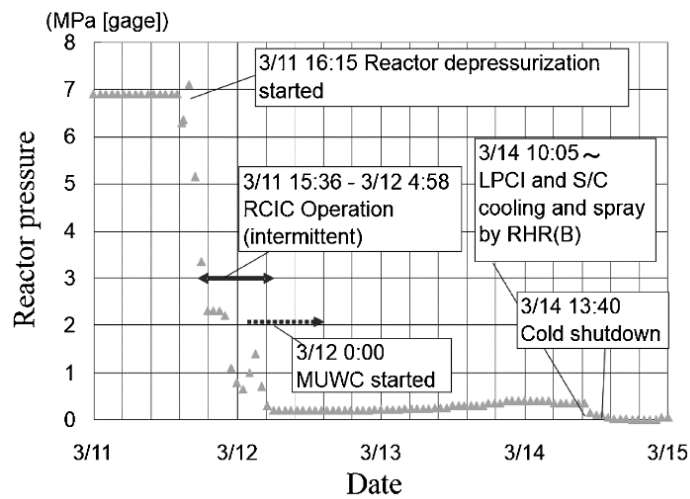

Figure 4 Reactor pressure of Unit 1

RCIC, LPCI, S/C, MUWC and RHR refer to the reactor core isolation cooling system, low-pressure core injection system, suppression chamber of primary containment vessel, make-up water condensate system, and the residual heat-removal system, respectively.

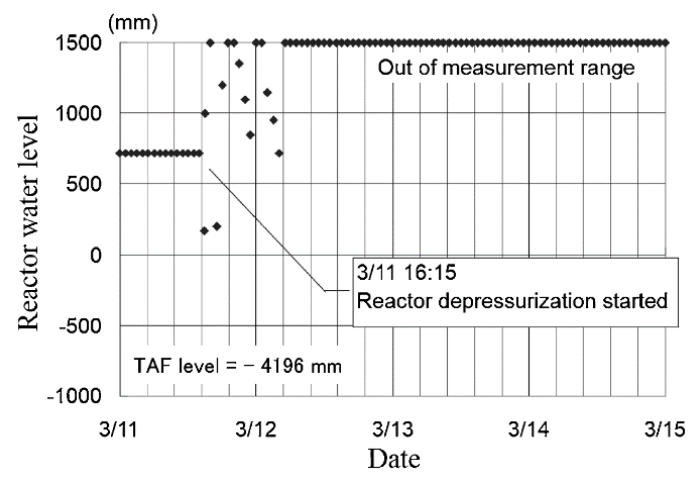

Figure 5 Reactor water level of Unit 1 TAF means Top of Active Fuel. 
in the containment vessel and major operations until the cold shutdown. First, at 6:20 on March 12 , after contacting the site emergency response organization, the operators injected low-temperature water from the MUWC into the $\mathrm{S} / \mathrm{C}$ via system $\mathrm{A}$ of the flammability control system (FCS) to mitigate the increase in the temperature. This was not what the FCS had been originally designed for, but it was a flexible response to utilize the MUWC for the FCS cooling. Next, after 7:10, the MUWC was switched from reactor water injection to containment vessel spray intermittently as an alternative measure to the original containment vessel spray using the RHR, and the increase in the containment vessel pressure was mitigated through the water spray to the dry well $(\mathrm{D} / \mathrm{W})$ and $\mathrm{S} / \mathrm{C}$.

Although these operations were effective in holding back an increase in pressure and temperature, these parameters increased again after shutdown. Therefore, in case the containment vessel exceeded the maximum working pressure, preparations for configuring the containment venting system were conducted. However, eventually, the situation was resolved before the containment vessel reached the maximum working pressure because system B of the RHR was restarted successfully at 1:24 on March 14 as a result of the remediation activity described later. Although an increase in pressure occurred on March 17, this was because water was transferred

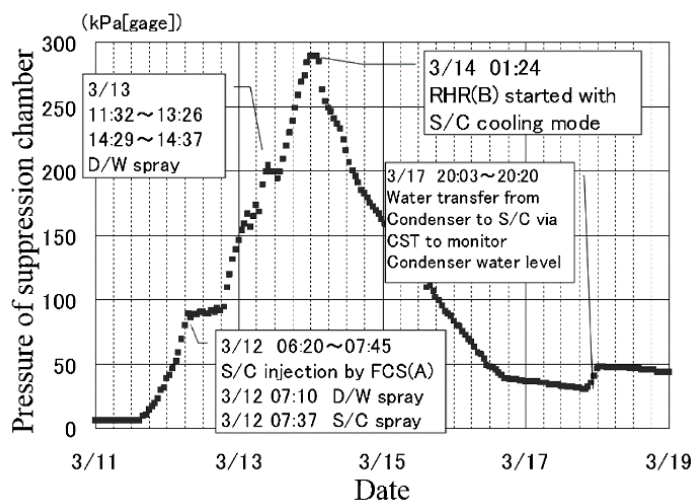

Figure 6 Pressure of Unit 1's primary containment suppression chamber $\mathrm{D} / \mathrm{W}, \mathrm{S} / \mathrm{C}$, and FCS refer to dry well, suppression chamber, and flammability control system, respectively.

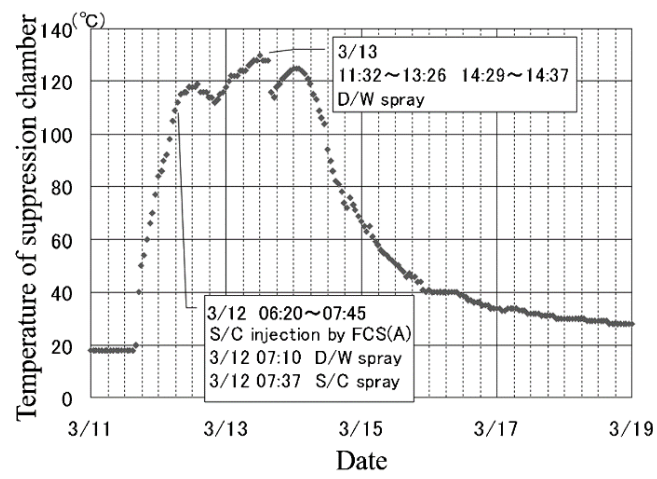

Figure 7 Temperature of Unit 1's primary containment suppression chamber $\mathrm{D} / \mathrm{W}, \mathrm{S} / \mathrm{C}$, and FCS refer to dry well, suppression chamber, and flammability control system, respectively. 
from the main steam condenser to the S/C via the condensate storage tank (CST), and not because a new event occurred on the reactor side.

The lessons learned from a series of responses include that a strategy should be developed to constantly increase the substitutability of response measures through the emergency response.

Concerning the reactor water injection, although RCIC was the only measure employed initially because the reactor was in the high-pressure stage, depressurizing the reactor increased the substitutability of water injection by a variety of means other than MUWC, which was used this time such as the utilization of a fire-extinguishing system. Meanwhile, it was possible that an unexpected situation, such as a failure of a response system, might occur over time. With this in mind, after ensuring the first response measure (water injection into the reactor using the RCIC system), action was taken continuously to progress the situation so that multiple alternative measures could be secured without becoming complacent about the first measure.

Furthermore, in order to mitigate the increase in containment vessel pressure, in addition to the alternative containment vessel spray, the number of alternative measures that could be chosen increased with time, such as by speeding up restoration of the RHR while preparing for containment venting as the next measure.

In the future, the emergency organization is required to enhance functions so that a strategy can be developed in the manner described above.

Furthermore, the function of collecting and analyzing information is essential for strategy planning as well as feeding back the execution results into strategy development. At Fukushima Daini, the strategic response as described above was possible because the functions of the instruments and control systems were secured and the site emergency response organization could ascertain the situation and predict the change in the situation based on data. In addition, it was also possible because the site emergency response organization and the main control room could share such information through establishing a means of communication and via a network and the consistency of the chain of command was maintained.

\section{(3) Summary of the lessons learned in the emergency response through operations}

The important lessons learned in operations that led to a successful response are summarized as follows:

First, in terms of implementing the emergency response effectively, it was important to provide appropriate assistance to the main control room as well as to secure the consistency of the chain of command through cooperation between the site emergency response organization and the main control room. From this perspective, the actions that were effective in the response at Fukushima Daini were as follows:

-The personnel with knowledge and experience in plant operations provided assistance to the operators in relation to technical assistance, liaison, and coordination.

-The liaison officers were dispatched from the site emergency response organization and stationed in the main control room so that the operators could concentrate on monitoring and operations, and the emergency response organization and the main control room could share information closely to secure the chain of command.

-The conditions of major safety facilities and the status of water injection into reactors were shared between the main control room and the site emergency response organization, and were also visibly posted in the emergency response organization so that all responders could maintain a common perception/understanding of events as they unfolded.

Next, as part the emergency response, the strategy of increasing the substitutability of response measures while constantly learning new information and predicting the changes was effective. With the response to a situation exceeding the anticipated conditions in mind, it is 
important to enhance the functions related to information analysis and strategy planning in the emergency response organization going forward.

In this regard, the following actions were taken at Fukushima Daini:

-The reporting and communication systems were maintained so that it was possible to understand the situation and predict changes based on the data, and it was ensured that such information could be shared between the site emergency response organization and the main control room.

-Concerning reactor water injection and containment vessel cooling, a strategy was devised whereby the substitutability of the response measures could be constantly increased based on an understanding of the situation and prediction of changes.

\section{Restoration Operations and the Lessons Learned}

\section{(1) On-site damage check}

In order to restore lost safety functions using limited human and material resources, the restoration operations should be prioritized and safely executed. For this purpose, the extent of damage at the site needs to be checked first. However, because the damaged area might have been flooded again due to tsunami waves that arrived repeatedly, dispatching the responders to the field immediately was delayed. After establishing the necessary means to secure safety, such as methods for collecting tsunami information, monitoring the situation at the site and the change in water level and issuing emergency evacuation instructions, the responders were dispatched to the damaged area around 10:00 pm. It took approximately seven hours after the tsunami hit for the responders to be dispatched to the field. In addition, in the on-site check conducted after that in the darkness, it was necessary to move carefully, avoiding scattered rubble and openings into the sea. Therefore, it took further time to reach the damaged facilities and check the situation. Including this, it took a total of seven more hours after the responders were dispatched to the field until the on-site check was completed.

Thus, as a lesson, it should be considered when designing emergency activities that ensuring the safety of responders and securing a route to the field under such an emergency situation could be difficult, and fully comprehending the damage situation can take considerable time.

In this way, the on-site check continued until around 5:00 am on March 12, and the information on damaged systems was collected at the site emergency response organization for analysis. When the components required to restore the A and B systems of the RHR of Units 1, 2 and 4 were compared, the power-supply facilities for auxiliary components were totally lost, and there was no difference between the two systems. However, as Table 1 shows, it was found that there were fewer pump motors that required replacement in the B system, and it was determined that the B system would be the subject of prioritized restoration. In addition, as part of the restoration method, it was determined by the site emergency response organization that the submerged pump motors would be replaced and temporary cables would be placed to supply electricity to the electric motors from the power panels that were not submerged or from mobile power vehicles.

\section{(2) Emergency procurement of restoration materials}

At the request of the site emergency response organization, the headquarters emergency response organization in Tokyo and Kashiwazaki Kariwa Nuclear Power Station (hereinafter referred to as "Kashiwazaki Kariwa") were in charge of the procurement and transportation of the materials required for restoration.

The major materials sent to Fukushima Daini were electric motors, power cables, mobile 
power vehicles, portable transformers, and light gas oil as the fuel for mobile power vehicles. All these materials, except for motors, could be procured relatively easily because they were highly versatile. However, for the three motors that needed replacement, it was necessary to find motors that were the same or that had similar specifications. For two out of the three motors, as suitable ones were found in the manufacturer's factory stock, three motors, including one spare motor, were shipped from Komaki Airport to Fukushima Airport by the Self-Defense Forces between 9:30 pm and 10:07 pm on March 12 and then carried by truck to arrive at Fukushima Daini at 6:33 am on March 13. For the remaining motor, because the one used at Kashiwazaki Kariwa was found to be suitable, two motors, including one spare motor, were uninstalled and then carried by truck to arrive at Fukushima Daini in the early morning of March 13.

In this way, the materials required for emergency restoration of the RHR were ready by 7:00 am on March 13. Land transportation took a long time because National Route 6 was cut off and the trucks were forced to detour due to landslides caused by the earthquake and inundation caused by the tsunami, the guide to the alternative route gave some incorrect directions resulting in a longer detour than necessary, and cell phones could not be used, making communication between the transportation team and the site emergency response organization difficult. Preparing for such situations is also an important lesson for the future.

The site emergency response organization asked the headquarters emergency response organization to arrange for the transportation of water to prevent running out of a source water for injection into the reactor, assuming a situation in which the restoration of the RHR would be delayed. However, this transportation did not come about because it was impossible to secure a way of transporting such a large amount of water. Although this problem was solved by the site emergency response organization, which decided to temporarily restore the system for taking subsoil water from the Kido river, it is necessary to fully consider which materials can be transported in an emergency, the transportation method of such materials, and the securement and storage of non-transportable materials at the power station in advance.

\section{(3) Restoration of RHR}

The full-scale restoration of the RHR was implemented on March 13, when the required materials were delivered from outside the power station. Using the road in the station, where the passage was ensured by the removal of rubble by heavy machinery the previous day, the required materials and equipment were carried into the site. In Units 1 and 4, the RHRC pump motors were replaced for cooling system B of the RHR. In addition, in Unit 1, the motor for a pump of the EECW was also replaced.

Furthermore, in parallel with these operations, the temporary restoration of the power system for operating the pumps was also conducted. Figure 8 shows the outline of the configuration of the temporary power system. In Units 1, 2 and 4, the power panels for supplying electricity to the pump motors of the RHRC, RHRS, and EECW, which were placed in the seawater heat-exchanger buildings (Hx Buildings), were totally broken by the tsunami. Therefore, the electricity was supplied to these motors from the power panels of Unit 3 and Rad-Waste Building, which were not underwater, or from the mobile power vehicles placed near the facilities via portable transformers. The temporary cables used for this restoration operation had a total length of approximately $9 \mathrm{~km}$ and were installed manually by approximately 200 people in one day on March 13.

After these operations were completed, the RHR of Unit 1 was restarted at 1:24 on March 14 to initiate heat removal from the reactor and the containment vessel. Finally, the cold shutdown of all reactors was completed by 7:15 on March 15 . 


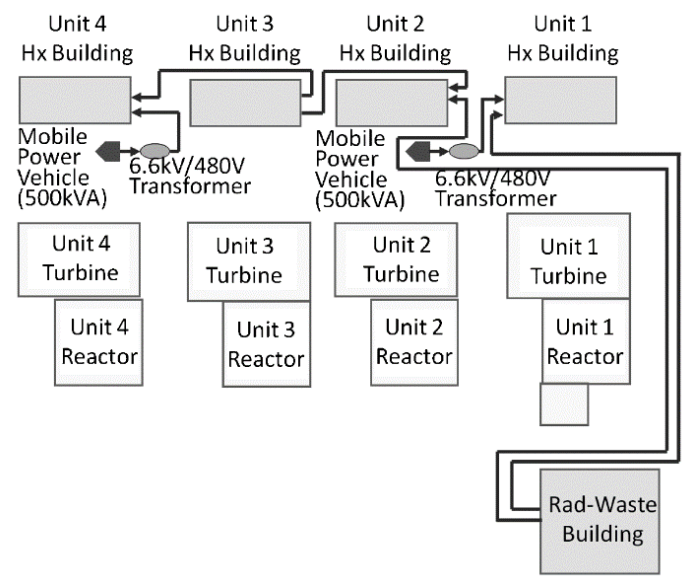

Figure 8 Layout of mobile power vehicles and temporary cables used for the recovery of cooling systems

Hx Building refers to the Heat Exchanger Building, where cooling facilities, including heat exchangers and pumps, are located.

\section{(4) Securing of stable cooling after restoration}

Although one system of the RHR was restored in each reactor and cold shutdown was achieved, there was a possibility that the means of heat removal would be lost again if the restored system failed because there was no spare heat-removal system in this situation. In addition, the possibility of deterioration in the insulation or a fire was also a concern because of the sea salt particles that had become attached to the electric facilities.

Therefore, while the restoration of standby facilities was being continuously undertaken, the vibration diagnosis, analysis of the components and cleanliness of lubricants, and diagnosis based on infrared thermography had been conducted very frequently on the restored facilities since March 14 to maintain their reliability. Among the pumps that were operable in spite of once being underwater, some experienced an increase in vibration in the vicinity of the bearings around May because of foreign materials contaminating the lubricant. Therefore, the bearings and lubricant in these pumps were replaced.

In addition, transportation of the materials for continuing the restoration work and the transportation and storage of fuel for the mobile power vehicles and service cars were needed, and some emergency response personnel were assigned to carry out these duties.

\section{(5) Summary of the lessons learned in the restoration work}

The important lessons learned in the restoration work are summarized as follows from the viewpoint of the operations and logistics supporting such operations:

The lessons learned in the restoration work are as follows:

-It is important that the condition of damaged facilities be verified in the on-site investigation and that the emergency response organization works on the restoration after clearly determining the priority of restoration operations.

-It is necessary to consider the means of securing safety in advance, assuming that on-site activities are taking place during an emergency.

-Considering that it may be impossible to dispatch responders to the damaged area at an early stage of the emergency and the on-site investigation and restoration activities may be restricted, it is important to take measures in advance to cope with the emergency even if 
on-site activities cannot be expected for a certain period of time after initial motion. In the example of Fukushima Daini, safety was temporarily secured by adopting an alternative means of water injection using a permanent facility. This measure provided sufficient time to perform restoration operations.

-It is important for the power station employees in charge of emergency response to have the skills required for emergency restoration work so that they can respond at any time, including on holidays/weekends and in the evenings.

-Facility diagnostic and repair techniques are required in order to operate the restored facilities stably for long periods after emergency restoration.

The lessons learned regarding logistics are as follows:

-Although the emergency procurement and transport could barely function as a result of flexible response, drastic improvement is required in the transportation system, as well as ascertaining the procurement and transport status and management of such information, and the means of communication between the transportation team and site emergency response organization.

-Concerning the activities conducted outside the power station, it is important to simulate the response to complex situations encountered in conjunction with natural disasters in advance.

-It is necessary to store important materials in the power station, assuming that the transportation of materials to the power station may be interrupted.

-It is necessary to prepare sufficiently for the transportation of materials in an emergency, such as organizational systems and radiation protection education for transportation personnel.

-It is necessary to establish the means to transport light gas oil and gasoline to the power station as well as to temporarily store and handle such dangerous materials in the power station in a safe manner

\section{Activities Supporting Long-Term Emergency Activities}

Although the cold shutdown of all reactors was achieved in Fukushima Daini on March 15, as described above, the activities needed to maintain a safe shutdown state continued for a long period afterward. The responders who stayed at the power station for emergency response were allowed to go home on a rotating basis starting on March 24, which was approximately two weeks after the occurrence of the event. However, even after that, many responders took turns sleeping at the power station continuously to prepare for unforeseen circumstances.

To support these long-term activities, it was necessary to cope with various issues.

First, most power station employees lived locally with their families and needed to confirm the safety of their family members and the status of their homes. Eighty-two percent of the employees lived within a twenty-kilometer radius of Fukushima Daiichi, and their families were required to evacuate. In addition, eight employees lost relatives due to the earthquake. Furthermore, forty-six percent of all employees experienced damage to their homes, ranging from total collapse to partial collapse. In order to continue emergency activities under such circumstances, it was essential to confirm the situations of the families and the condition of the homes of the responders so that necessary measures could be taken. However, it actually took ten days for all responders to contact their families; this needs to be improved further.

There were responders who developed sudden deafness or symptoms of depression due to the stress of emergency activities and required psychological support. In addition to an interview with an industrial physician and nurses, medical specialists were invited to the power 
station on April 16 and May 5 to conduct questionnaire investigations and interviews. As a result, among approximately 500 emergency responders of Fukushima Daini, more than 100 responders were diagnosed with post-traumatic stress disorder (PTSD), and periodic diagnoses were made by the medical specialists starting in May.

In addition, risk management from the aspect of hygiene was needed because many responders conducted activities and slept in the important seismically isolated building where the site emergency response organization was placed. In this form of risk management, the activities such as the procurement of food and drinking water, securing a water supply for toilets and showers through restoration of deep wells and water pipes, obtaining bedclothes, installation of laundry facilities, and management of household garbage were included.

Since almost none of the above responses had been prepared for or experienced before, they were undertaken flexibly by the teams in charge of general affairs in the emergency response organization. However, long-term emergency activities cannot be conducted without these responses, so it is necessary to take advantage of the above to prepare for the future.

\section{Reflection in the Emergency Management System}

\section{Issues in the Emergency Management System}

Although lessons were extracted from the emergency responses made at Fukushima Daini as described in the previous chapter, it is necessary to consider the way in which the entire emergency management system is implemented in order to take advantage of these lessons. This is because emergency activities are highly interconnected and management of the entire system is important in order to conduct activities effectively within a limited time and with limited human and material resources. In addition, it was revealed from the analysis described in the previous chapter that there were important functions that needed drastic enhancement, such as strategic and logistics functions, in order to cope with the situation exceeding the anticipated conditions.

The emergency organization of Fukushima Daini set up in this emergency situation was as shown in Figure 1. This organization is configured so that twelve functional teams exist in parallel under the chief of the headquarters of the site emergency response organization (Site Superintendent). It can be said that this structure enables each team to conduct activities in parallel and with the utmost promptness, according to the procedures and guides established in advance, in the case of an event within the range of the anticipated conditions. However, in situations exceeding the anticipated conditions where the procedures and guides cannot be applied without modification, it is difficult to cope with the changes in situation flexibly because the chief is required to manage a much wider range of issues alone. In Fukushima Daiichi, which had the same structure as shown in Figure 1, this problem surfaced as the situation there was far more severe than that experienced in Fukushima Daini.

As analyzed in the previous chapter, in the emergency response made at Fukushima Daini, it was important to initiate the response to the situation with limited information and limited human and material resources, enhance the situational awareness and respond to the situation while revising the response strategy. In other words, the function to develop and revise strategies (strategy-planning function) was important. However, these responses were made on an ad-hoc basis and were not assured as an emergency management system. In the structure shown in Figure 1, the functions were distributed so that information was collected by the information team, the plant behavior was predicted based on the information by the engineering team, the 
strategies related to operation were developed by the plant operation team, and the strategies for restoration were developed by the restoration team. Therefore, the functions to continuously conduct the activities such as the development of strategies and the revision of strategies through the analysis of the implementation status were not clearly determined. This needs to be improved first to realize an emergency management system which can cope with situations exceeding the anticipated conditions.

In addition, as a result of the analysis described in the previous chapter, it became clear that there were many issues to be solved concerning activities related to logistics and activities supporting long-term emergency initiatives. Because both are functions that have not yet been clearly defined, it is necessary to reflect the respective lessons related to these activities after positioning them clearly in the emergency management system.

\section{Application of the Incident Management System}

It is considered valuable to study the application of the Incident Command System ${ }^{4)}$ (ICS) developed in the United States for solving the issues concerning the emergency management system described in the previous section.

ICS is an emergency management system that was created in the US to elucidate how an emergency organization can function to enable activities in a scenario where conditions are constantly changing and under circumstances where it is not clear to what extent the situation will spread, such as wildfires and natural disasters. The effectiveness of its functions has been increased by reflecting the actual experience in disaster response, including the response to Hurricane Katrina in $2005^{5}$.

Figure 9 shows the basic configuration of the management functions of ICS. The management functions consist of the following four function modules under the Incident Command (commander) : Operations (execution team), Planning (intelligence and planning team), Logistics (logistics team), and Finance/Administration (finance and administration team). ICS is designed to cope flexibly with the changes in a situation by maintaining, reinforcing and reducing the personnel of each function module or the organizations in the module according to the situation.

The configuration of this management function is consistent with the strategy planning, logistics, and general affairs functions supporting long-term activities, which are identified as necessary based on the lessons learned at Fukushima Daini, and can be a good basis on which improvements can be considered. It is also worth considering as a management system that can handle situations exceeding the anticipated conditions because the functions are configured modularly to increase the ability to respond to changes in the situation.

However, there are no precedents in which ICS was applied to nuclear emergency

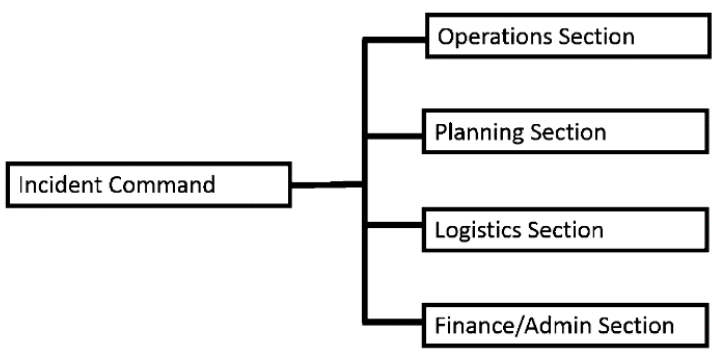

Figure 9 High-level functional structure of the Incident Command System 


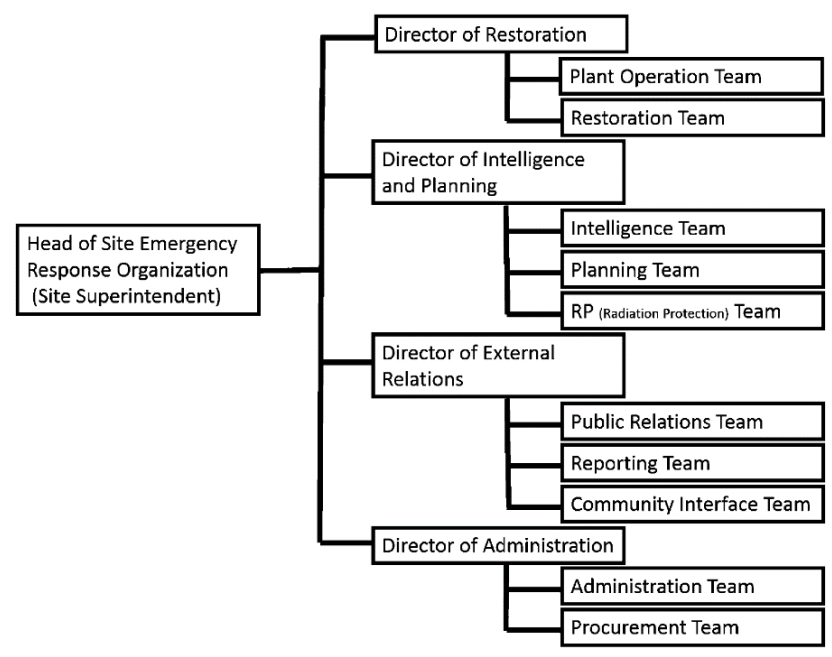

Figure 10 Functional structure of an improved site emergency response organization applying the ICS concept

management systems in the United States or Japan. Therefore, we considered the application of ICS from our own perspective, while considering the particular characteristics of nuclear emergency situations. Figure 10 shows the basic configuration of the nuclear emergency response functions to which ICS is applied. Under the head of the site emergency response organization, the persons responsible for the strategy-planning (intelligence and planning) function, execution function (such as operation and restoration), external contact (such as notifications to the central and local governments and dealing with the press), and general affairs function are positioned. This configuration basically follows ICS, but two changes were made so that it can function as a site emergency response organization.

The first change is that the external contact function was positioned as one team. This is because the activities in collaboration with the central and local governments and the activities related to the transmission of information via the press, etc., are important in nuclear emergency situations, as with a conventional nuclear emergency response organization.

The second change is that the logistics function is not positioned as a team in the site emergency response organization. This is to allow the site emergency response organization to focus on the activities conducted at the site. Instead, logistics is positioned as an important mission of the headquarters emergency response organization, which sets up the logistics bases in distant places outside the precautionary action zone (PAZ) and which is assigned the function to procure and transport necessary materials.

In the following sections, the direction of the reinforcement of respective functions are discussed reflecting the lessons learned at Fukushima Daini, based on the emergency management system to which ICS is applied.

\section{Intelligence and Planning Function (ICS's Planning Function)}

It is said that the important features of ICS's planning function are the collection, evaluation, and display of information; planning of response activities; management of human and material resources; and documentation.

In the emergency response made at Fukushima Daini, the collection, evaluation, and display 
of information had already been established as matters of primary importance. Specifically, the site emergency response organization dispatched the liaison officers to the main control room to prevent discrepant information from being collected. Then, in the site emergency response organization, the information on the condition of major safety facilities and the status of water injection into the reactors were summarized from the information conveyed from the main control room and that obtained from the safety parameter display system (SPDS), and it was written out and displayed. In this way, the operators at the main control room and the personnel of the response organization had a common and shared perception of the situation.

This is called a "common operation picture," and its information is determined by the configuration of plant facilities and emergency facilities. Therefore, the standard format of the information should be created in advance so that it can be displayed on paper and in electronic media. The SPDS is useful as a tool for sharing important plant parameters. In addition, the lessons learned at Fukushima Daini show the importance of sharing the information obtained by interpreting the parameters (e.g., the prediction of an increase in the containment vessel pressure), the information on the operability of the facilities, and the information on important restoration activities. Therefore, preparing the common operation pictures as a tool is considered to be very useful. Furthermore, standardizing especially important matters and the method of displaying them from the information shown on the whiteboards in emergency drills as the common operation picture enables continuous improvement.

Figure 11 shows an example of a common operation picture. It summarizes important information for understanding the accident conditions, such as the picture of a reactor and a containment vessel in the center, the conditions of the reactor and its control as well as the conditions of the control of the containment vessel temperature and pressure on the upper side, and the predicted time when the reactor water level reaches TAF as well as the predicted time when containment venting is required on the lower side. Such information was not only written out

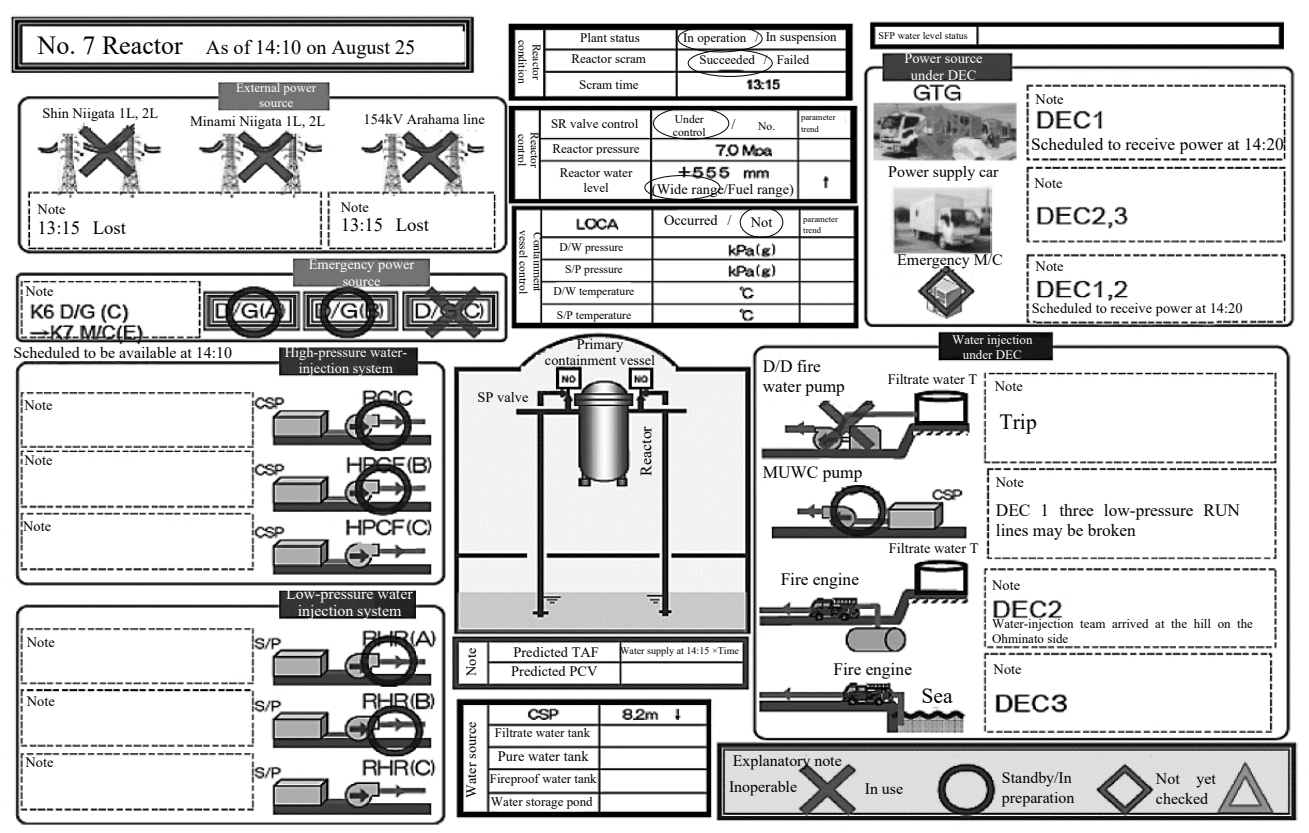

Figure 11 An example of a common operation schematic for information sharing among responders in a nuclear emergency 
on the whiteboard, but also distributed on paper so that it could be shared within the response organization of Fukushima Daini.

In the left portion of Figure 11, the information on the operability of the external power sources, emergency power sources, and high- and low-pressure water injection systems of the ECCS is summarized. The information on the operability of safety facilities was also written out, updated as needed, and shared at Fukushima Daini in a similar way as shown in Figure 2, and this also proved to be useful. In the right portion of Figure 11, the conditions that developed at major facilities related to power supply and water injection among severe accident-management facilities after the accident occurred at Fukushima Daiichi can be described. The word "DEC" in this figure represents the equipment that is usable under the design extension condition.

Furthermore, in terms of the information analysis and planning of response activities, in the emergency response made at Fukushima Daini, it was effective to constantly develop strategies that increased the substitutability of response measures while at the same time obtaining and understanding the information and predicting the changes. However, the engineering team shown in Figure 1 took charge of understanding the situations and predicting changes based on the plant parameters, the plant operation team took charge of the development of a response strategy in terms of operation, the restoration team was responsible for that strategy in relation to facility restoration, and the headquarters was responsible for making overall adjustments as needed. In order to reinforce this function further, a director should be assigned to the planning function to conduct information analysis and strategy planning in an integrated way.

In the meantime, the information team took charge of the acquisition of plant parameters and the collection of information on emergency response activities, which were utilized in information analysis as needed. It is preferable that this also be positioned and integrated as part of strategy planning.

In addition, as the lessons learned from the emergency response made at Fukushima Daini, it is important to plan strategies considering that on-site activities may initially be restricted for a certain period of time. It is preferable to prepare for the response by adopting a phased approach, where securing safety in the interim is enabled through a response using permanently installed facilities initially and then the substitutability of response measures is increased with the passage of time.

Figure 12 shows the concept of the phased approach, in which the emergency response is classified into three phases according to the time elapsed after the accident. In the first phase, mobile safety facilities cannot necessarily be expected due to constraints, such as limited human resources for on-site activities and the inability to dispatch responders to the field until their safety can be ensured. Therefore, the basic response should be conducted with permanently

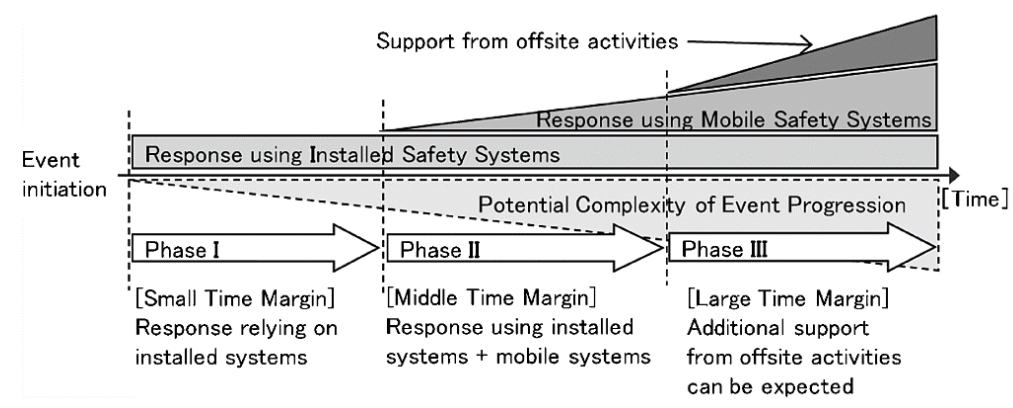

Figure 12 Concept of phased approach in emergency response 
installed facilities. In the emergency response made at Fukushima Daini, water injection into the reactors was maintained by using the RCIC and the MUWC first to secure temporary safety, which corresponds to the first phase.

In the second phase, restoration is promoted, utilizing materials such as the mobile facilities and spare items in the power station and measures for securing safety are added. In the third phase, the human and material resources from outside the power station are introduced to broaden the response as well as to ensure the continuity of safety securement. In the example of Fukushima Daini, because there were few materials and equipment available for restoration in the power station, the activities corresponding to the second phase could not be conducted sufficiently and the restoration activities corresponding to the third phase were conducted after the materials were delivered from outside the power station.

In addition, even if temporary safety is secured in the first phase, it is possible that secondary damage may spread as time passes, the safety facilities of the first phase may break down, a new problem may be found as a result of on-site investigation, etc. Therefore, it is important to continuously promote the diversification of response measures and expansion of substitutability during and after the second phase. In the example of Fukushima Daini, the response measures were added continuously in a scenario of spreading of flood damage, failure of restored safety facilities, and increase in the risk of electric fire.

The duration of each phase in an emergency situation differs depending on the situation of the accident. The strategies are developed in accordance with the phased approach concept, considering the prioritization of necessary activities. On the other hand, when designing the safety facilities or workforce configuration for emergency preparedness, it is necessary to set the estimated time of each phase as design conditions. It should be determined in consideration of important hazards, configuration of safety facilities and the geographical conditions of each power station. In the case of Fukushima Daini, it took half a day to gain access to the field and check the situation. Therefore, twelve hours after the occurrence of an accident could be a rough guide to the point at which the second phase can be expected to begin. In addition, considering the possibility that the areas outside the power station may also be in a confused state due to the influence of a significant disaster, seven days after a general disaster is considered to be a rough approximation of the amount of time that elapses before the third phase can begin.

\section{Operation and Restoration Execution Functions (Operation Functions of ICS)}

In the emergency response at Fukushima Daini, the main control room took charge of the strategy execution function from the viewpoint of operation and the restoration team took charge of this function from the viewpoint of facility restoration. In this emergency response, because the roles were divided, the operators operated undamaged facilities and the restoration personnel repaired damaged facilities, there were no special problems in their interfaces.

However, because the number of mobile safety facilities has been increasing under new regulatory standards and the number of important work-related interfaces, such as the installation of mobile facilities by the restoration personnel and the response operation utilizing such facilities by the operators, will increase, it is desirable that a director to execute functions be assigned to realize a more integrated response in the future.

In addition, as the lessons learned from the emergency response made at Fukushima Daini, the organization in charge of this execution function also needs to be prepared to ensure safety during emergency activities, such as securing working lights, communication means, and the 
removal of rubble to facilitate on-site activities. In addition, it is also necessary to enhance the skills required for emergency restoration work so that the response can be made at any time, including on holidays/weekends and in the evenings. Furthermore, it is also important to acquire component diagnosis and repair skills because restored facilities need to be operated stably for long periods after emergency restoration.

\section{Logistics Function}

In the emergency response made at Fukushima Daini, most logistics were not planned in advance, although they succeeded. Therefore, there are many lessons learned in this field, as follows:

First, most of the important restoration materials were procured through flexible response after the occurrence of the emergency situation. In order to enhance the ability to respond to situations exceeding the anticipated conditions, it is necessary to consider in advance the restoration materials required, in case the facilities important to safety are damaged, and prepare for their storage in the power station as well as the means of external procurement and transportation to the power station.

In the emergency response made at Fukushima Daini, difficulties were also experienced in the transportation of the restoration materials to the power station. It is necessary to develop a team with specialized logistics skills to enhance the response in terms of the transportation system, understanding procurement and transportation situations, the management of such information, and the means of communication between the transportation team and headquarters, etc.

In addition, especially when these activities are conducted outside the power station, the necessity of responding to complex situations due to a natural disaster needs to be assumed in advance. For example, in the emergency response made at Fukushima Daini, the transportation of restoration materials required for cold shutdown were delayed due to blockage of National Route 6 as a result of the earthquake and tsunami.

Furthermore, in order to assist restoration activities without interruption, it is necessary to develop the means of transporting light gas oil and gasoline to the power station as well as temporarily storing and safely handling these dangerous materials.

\section{General Affairs Function}

The general affairs function must also prepare for the possibility of a prolonged emergency response.

Based on the lessons learned in the emergency response at Fukushima Daini, the roles expected of the general affairs function include checking the safety of the emergency responders' families and the condition of their homes on their behalf, the construction of a mental care program, and the implementation of necessary measures in consideration of hygiene risks generated by the situation where many responders work and sleep in limited spaces. These matters were described in detail in Section 4 of the previous chapter.

\section{Conclusions}

Due to the tsunami caused by the Great East Japan Earthquake, Units 1, 2 and 4 at Fukushima 
Daini lost their heat-removal function completely, but the cold shutdown succeeded as a result of the restoration of the RHR through flexible activities. In this article, in order to reinforce the emergency management system of nuclear power stations, important success factors and issues that emerged during the emergency response were analyzed and extracted as lessons learned from Fukushima Daini, where an emergency situation exceeding the anticipated conditions was actually managed successfully.

As a result, it was found that the (1) strategy-planning function to develop strategies as well as to analyze the implementation status and revise the strategies, (2) logistics function, and (3) function to assist long-term emergency activities needed to be reinforced as the management system. Based on these findings, an emergency management system in which ICS was applied to the nuclear emergency response organization was suggested. ICS, which was developed in the United States mainly for disaster response, has achieved results in emergency activities under circumstances where it was not clear the extent to which the situation would spread. This is the first time that ICS has been applied to the management of nuclear emergencies in the US or Japan.

In addition, in applying ICS, the important points in the reinforcement of major functions were shown specifically, based on the lessons learned from the experience at Fukushima Daini. Examples of such important points are the clarification of who will be in charge of information analysis and strategy design; reinforcement of information sharing means including the utilization of a common operation picture; strategy design through a phased approach, clarification of who will be in charge of the execution of strategies such as operation of the plant, mobile facilities, and restoration activities; development of hands-on work skills among power station employees in charge of emergency response; development of a team with specialized logistics ability; improvement of material storage and procurement; and care for the personnel who are engaged in a long-term response as wells as care for their families.

It is expected that this improvement will enable a more flexible response to situations exceeding anticipated conditions. The nuclear emergency management system to which ICS was applied was introduced to Kashiwazaki Kariwa Nuclear Power Station and has been improved on a daily basis through training. The improvement under this management system has been producing good results in training sessions, which are conducted without notifying the participants of the scenario in advance and assume such a severe situation as the occurrence of multiple failures, which could lead to severe accidents occurring in several reactors. In such training programs, the site emergency response organization functioned properly to control the situations.

We intend to conduct training continuously on the management of nuclear emergencies utilizing ICS to further improve the ability to respond to the situations exceeding the anticipated conditions and to work on improving safety.

\section{References}

1) Tokyo Electric Power Company, Fukushima Nuclear Accident Investigation Report (2012).

2) Japan Nuclear Technology Institute, Tokyo Denryoku Fukushima Daini Genshiryoku Hatsudensyo Tohokuchiho Taiheiyo-oki Jishin oyobi Tsunami ni taisuru Taiojokyo no Chosa oyobi Chushutsusareru Kyokun ni Tsuite (2012). [in Japanese]

3) Atomic Energy Society of Japan, Fukushima Dai-ichi Genshiryoku Hatsudensho Jiko sono Zenbo to Asu ni Muketa Teigen, Maruzen-shuppan, Tokyo, ISBN 978-4-621-08743- 5(2014). [in Japanese]

4) Federal Emergency Management Agency, Introduction to the Incident Command System (ICS 100) (2010).

5) A. M. Howitt, H. B. Leonard, Managing Crises, CQ Press, Washington, D.C., ISBN 978-0-87289-570-6 (2009). 